University of Louisville

ThinkIR: The University of Louisville's Institutional Repository

Electronic Theses and Dissertations

6-1924

\title{
The measurement of the specific inductive capacities of various liquid dielectrics.
}

Obe Bromfield Ellis

University of Louisville

Follow this and additional works at: https://ir.library.louisville.edu/etd

\section{Recommended Citation}

Ellis, Obe Bromfield, "The measurement of the specific inductive capacities of various liquid dielectrics." (1924). Electronic Theses and Dissertations. Paper 400.

https://doi.org/10.18297/etd/400

This Master's Thesis is brought to you for free and open access by ThinkIR: The University of Louisville's Institutional Repository. It has been accepted for inclusion in Electronic Theses and Dissertations by an authorized administrator of ThinkIR: The University of Louisville's Institutional Repository. This title appears here courtesy of the author, who has retained all other copyrights. For more information, please contact thinkir@louisville.edu. 


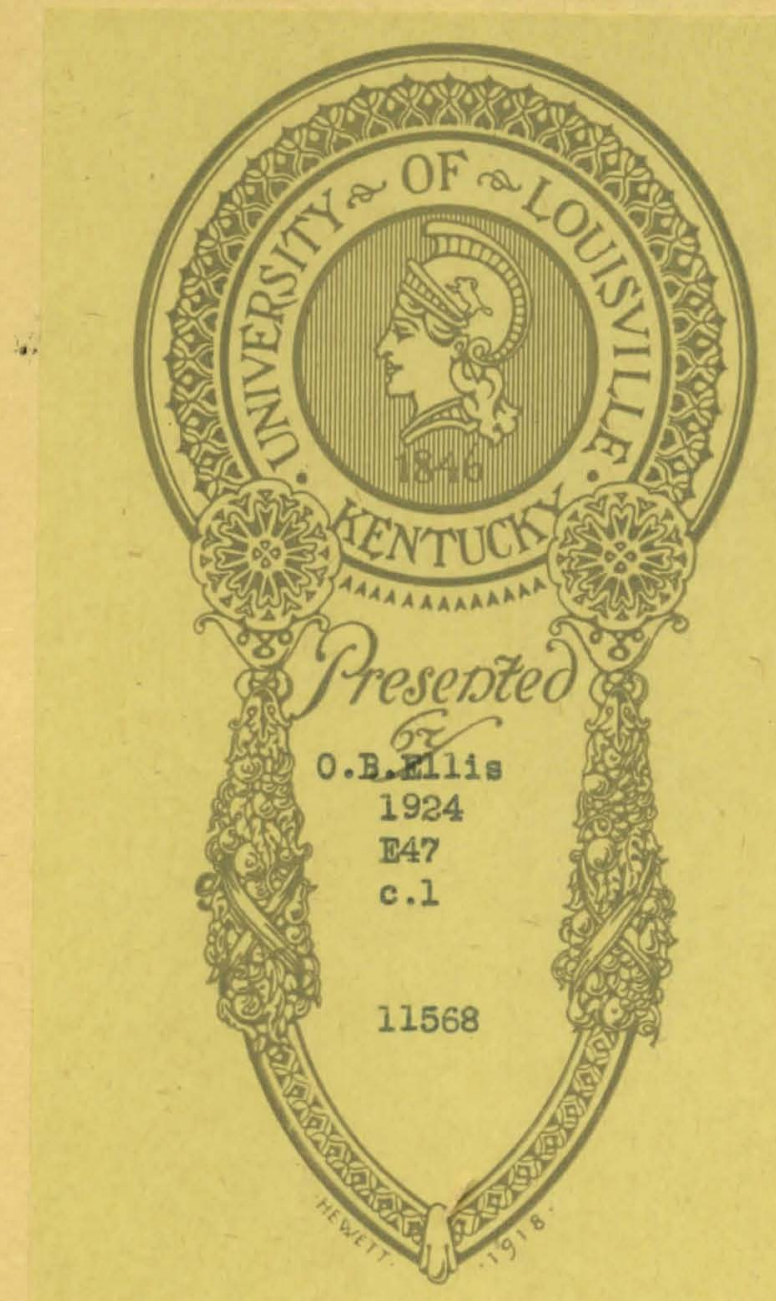




\title{
THE MEASUREMENT OF THE SPECIFIC INDUC- TIVE CAPACITIES OF VARIOUS LIQUID DIELECTRICS
}

\author{
A THESIS \\ SUBMITTED TO THE FACULTY OF THE \\ GRADUATE SCHOOL OF ARTS AND SCIENCES \\ OF THE UNIVERSITY OF LOUISVILLE
}

IN PARTIAL FULFILMENT OF THE REQUIREMENTS

FOR THE DEGREE OF MASTER OF SCIENCE

DEPARTMENT OF PHYSICS

OBE BROMFIELD ELLIS

JUNE 1924 


\section{THE MEASUREMENT OF THE SPECIFIC INDUCTIVE CAPACITIES OF VARIOUS LIQUID DIELECTRICS}

The name inductivity, or dielectric capacity, or specific inductive capacity is given to the ratio between the capacities of two condensers of the same size and shape, one of them filled with the specified dielectric, and the other an air condenser. The inductive capacity of dry air at standard conditions is usually taken as the standard. Therefore, the measurement of the specific inductive capacity of any given dielectric resolves itself into the measurement of the capacity of a condenser with the given material as dielectric.

The capacity of a condenser may be measured by comparing it with the capacity of a standard condenser. There are numerous methods of comparing these capacities, the more important of which are outlined below.

(a) The Electrometer Method. The condenser of unknown capacity is charged to a certain potential. It is then made to share its charge with a condenser of known capacity, and the potential to which the charge sinks is then measured. The original capacity is calculated since it will bear the same ratio to the joint capacity of the two as the final potential bears to the original potential. If $\mathbf{C}$ represents the unknown capacity, $\mathbf{c}$ the known capacity, $\mathbf{P}$ the original potential, and $\mathbf{p}$ the final potential, then

$$
\frac{\mathbf{C}}{\mathrm{C}+\mathbf{c}}=\frac{\mathbf{p}}{\mathbf{P}}
$$

or

$$
\mathbf{C}=\frac{\mathbf{c} \mathbf{p}}{\mathbf{P}-\mathbf{p}}
$$


(b) The Wheatstone Bridge Method. Two condensers of capacity $\mathbf{C}$ and $\mathbf{c}$ are connected in the two arms of a Wheatstone bridge, and the two resistances, $\mathbf{R}$ and $\mathbf{r}$, are adjusted so that there is no deflection of the galvanometer either on charge or on discharge. Then the larger capacity acts as the smaller resistance, and the following relation holds

$$
\mathbf{C}: \mathbf{c}=\mathbf{r}: \mathbf{R}
$$

(c) Leakage Through a High Resistance Method. The condenser is charged and is allowed to discharge through a high resistance of the order of twenty megohms and upwards for a known time, $\mathbf{t}$. If $\mathbf{C}$ is the capacity of the condenser, $\mathbf{r}$ the high resistance, $\mathbf{Q}$ the value of the original charge, and $\mathbf{q}$ the value of the final charge after leakage, then

$$
C=\frac{t}{r \log _{e} \frac{Q}{q}}
$$

(d) The Ballistic Galvanometer Method. An air condenser of unknown capacity or known capacity is charged to a known potential, and is then discharged through a ballistic galvanometer, and the deflection is observed. The same condenser is filled with a dielectric whose specific inductive capacity is to be measured, is charged to the same potential and is then discharged through the ballistic galvanometer, the deflection being noted. Then the ratio of the deflection with the condenser filled with the dielectric whose specific inductive capacity is to be measured to the deflection of the air condenser will be the inductive capacity of the dielectric.

The latter method was used for this work. Three parallel plate condensers of the type commonly used in wireless telegraphy were connected in parallel. This condenser was then placed in a glass vessel, sealed, and dried for twenty-four hours with calcium chloride. It was 
then charged to a potential of 38.8 volts, discharged through the ballistic galvanometer and the deflections very carefully measured. The average of thirty readings, fifteen on each side of the zero, was taken as the most probable value of the deflection. The glass vessel was then filled with the various dielectrics, liquids being used entirely, and the deflections were again measured as before.

A Leeds and Northup Type HB D'Arsonval Ballistic Galvanometer was used. This galvanometer had a sensitivity of .0364 microfarads per centimeter with a scale distance of 52.5 centimeters. It was found that if the discharge key A, figure 1, was pressed and held down for any length of time, a deflection was observed which was not due to the discharging of the condenser. The cause of this deflection was looked for and was found to be due to a thermal couple at the key which was caused by the heating of the junction by contact with the hand. This was eliminated by tapping the key and measuring the instantaneous discharge of the condenser through the galvanometer, which gave consistent results.

It was very difficult to obtain samples of the various dielectrics that were pure enough to give consistent results. In addition to those named below, water and linseed oil were tried, but these were conducting to such an extent as to render them useless for this work. The air was dried for twenty-four hours before any readings were taken. The turpentine and sperm oil were of a very good quality, and the results obtained from these are of a reasonable order of accuracy. There were no tables to be found giving results on gasoline, and as the gasoline used was a commercial product of rather low specific gravity the value obtained probably has considerable error. The benzene had an odor more of gasoline than of benzene, and its specific gravity was also too low for the pure substance. The results are tabulated, following.

In conclusion I wish to express my appreciation to Dean Warwick M. Anderson who suggested the problem and to Dr. Leo G. Raub whose kind assistance and criticism during my work has been of great value. 

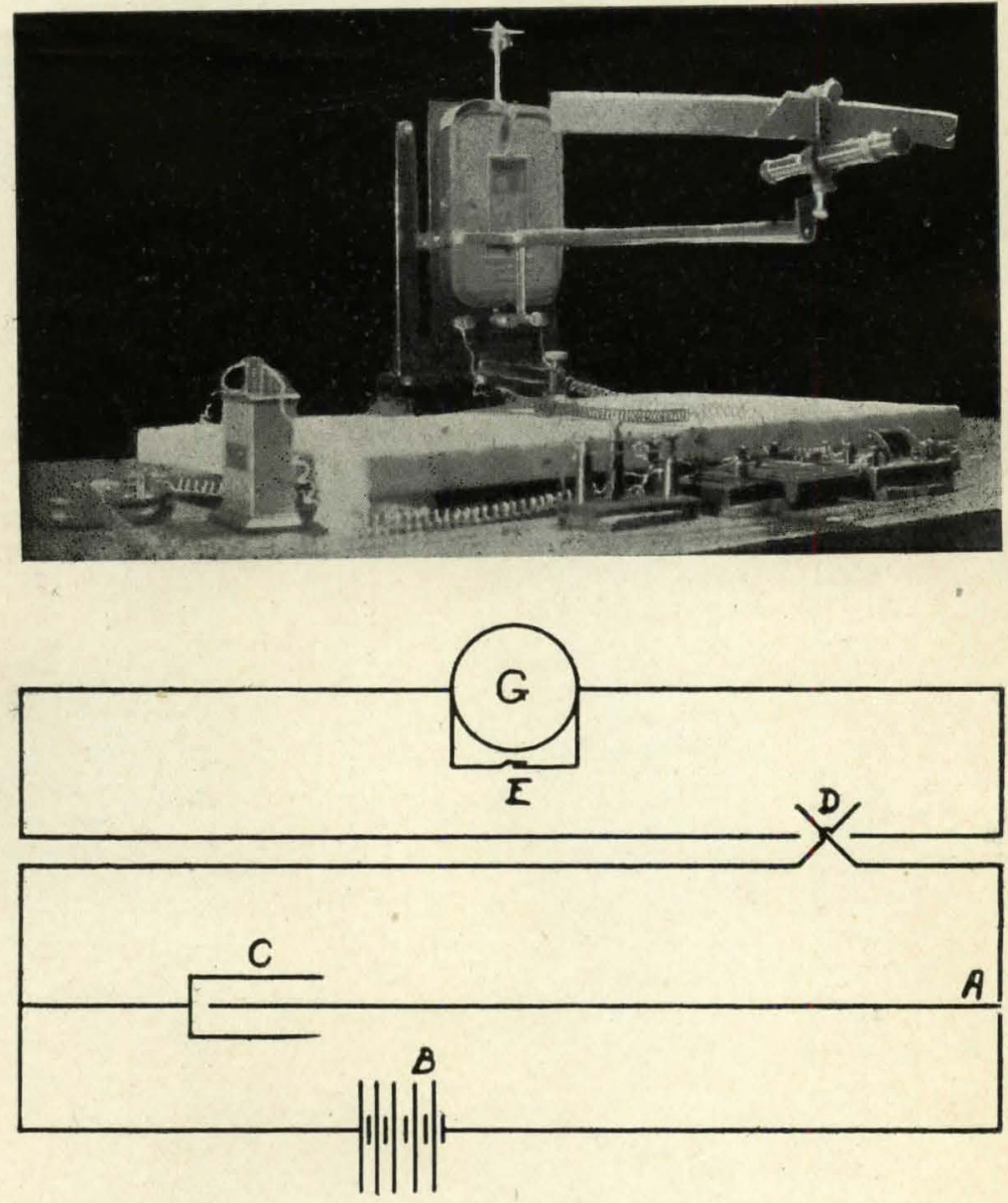

A-Charge and Discharge Key

B-Batteries

C - Condenser

D-Reversing Switch

E-Damping Key

G-Galvanometer 


\section{DRY AIR}

Temperature $22^{\circ}$ Centigrade

Deflections

Right

4.00

4.02

4.00

4.10

4.10

4.10

4.00

4.10

4.03

4.09

4.10

4.10

4.10

4.00

4.08
Potential 38.8 volts

Left

4.00

4.00

4.02

4.00

4.09

4.12

4.15

4.08

4.00

4.12

4.15

4.10

4.10

4.10

4.09
Average

4.000

4.010

4.010

4.050

4.095

4.110

4.075

4.090

4.015

4.115

4.125

4.100

4.100

4.050

4.085

Average deflection 4.068 centimeters 


\section{TURPENTINE}

Temperature $21.3^{\circ}$ Centigrade Potential 38.8 volts Deflections

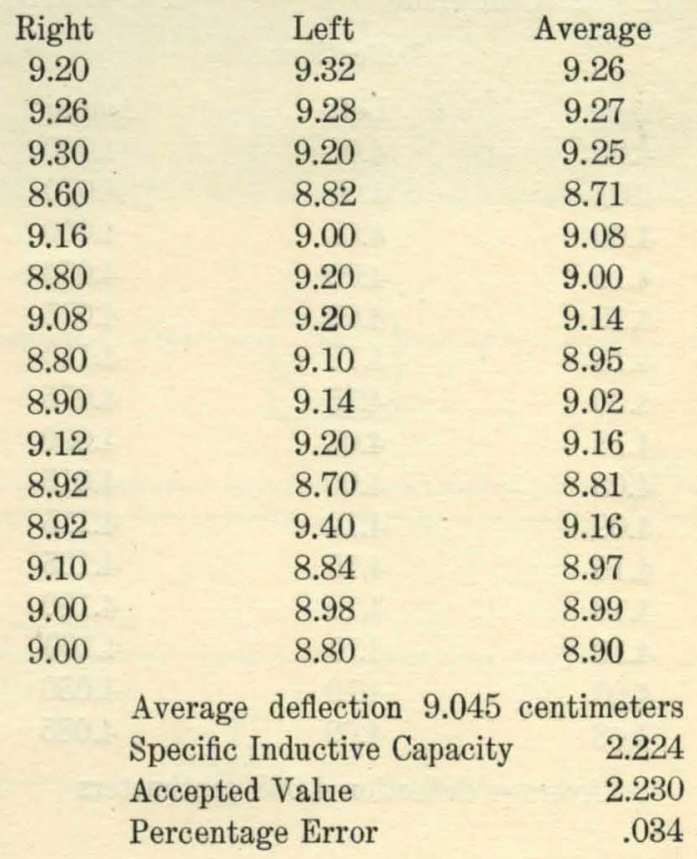




\section{SPERM OIL}

Temperature $18^{\circ}$ Centigrade Potential 38.8 volts Deflections

\begin{tabular}{|c|c|c|}
\hline Right & Left & Average \\
\hline 13.10 & 13.30 & 13.20 \\
\hline 13.10 & 13.50 & 13.30 \\
\hline 13.40 & 13.28 & 13.34 \\
\hline 13.10 & 13.00 & 13.05 \\
\hline 12.94 & 13.36 & 13.15 \\
\hline 12.86 & 13.50 & 13.18 \\
\hline 12.90 & 13.10 & 13.00 \\
\hline 13.20 & 13.18 & 13.19 \\
\hline 13.40 & 13.30 & 13.35 \\
\hline 13.30 & 13.00 & 13.15 \\
\hline 12.80 & 13.60 & 13.20 \\
\hline 13.30 & 13.40 & 13.35 \\
\hline 12.90 & 13.02 & 12.96 \\
\hline 12.80 & 13.60 & 13.20 \\
\hline 12.90 & 13.60 & 13.25 \\
\hline \multicolumn{3}{|c|}{ Average Deflection 13.19 Centimeters } \\
\hline \multicolumn{2}{|c|}{ Specific Inductive Capacity } & 3.22 \\
\hline \multicolumn{2}{|c|}{ Accepted Value } & 3.17 \\
\hline & & .15 \\
\hline
\end{tabular}




\section{GASOLINE}

Temperature $20.75^{\circ}$ Centigrade Potential 38.8 Volts Deflections

\begin{tabular}{ccc} 
Right & Left & Average \\
7.80 & 7.70 & 7.75 \\
7.84 & 7.70 & 7.77 \\
7.86 & 7.78 & 7.82 \\
7.90 & 7.72 & 7.81 \\
7.76 & 7.66 & 7.71 \\
8.06 & 7.80 & 7.93 \\
7.80 & 7.70 & 7.75 \\
8.00 & 8.00 & 8.00 \\
7.80 & 7.70 & 7.75 \\
7.90 & 7.72 & 7.86 \\
7.88 & 7.74 & 7.81 \\
8.00 & 7.86 & 7.93 \\
7.94 & 7.76 & 7.85 \\
8.02 & 7.72 & 7.87 \\
8.00 & 7.78 & 7.89 \\
\multicolumn{3}{c}{ Average Deflection 7.84 Centimeters } \\
\multicolumn{3}{c}{ Specific Inductive Capacity } \\
\end{tabular}


BENZENE

Temperature $21.5^{\circ}$ Centigrade Potential 38.8 volts Deflections

\begin{tabular}{|c|c|c|}
\hline Right & Left & Average \\
\hline 8.00 & 8.32 & 8.16 \\
\hline 8.00 & 8.22 & 8.11 \\
\hline 8.19 & 8.17 & 8.18 \\
\hline 8.10 & 8.20 & 8.15 \\
\hline 8.12 & 8.34 & 8.23 \\
\hline 8.30 & 8.10 & 8.20 \\
\hline 8.32 & 8.24 & 8.28 \\
\hline 8.10 & 8.36 & 8.23 \\
\hline 8.30 & 8.48 & 8.39 \\
\hline 8.18 & 8.10 & 8.14 \\
\hline 8.22 & 8.40 & 8.31 \\
\hline 8.12 & 8.30 & 8.21 \\
\hline 8.28 & 8.30 & 8.29 \\
\hline 8.34 & 8.20 & 8.27 \\
\hline 8.10 & 8.10 & 8.10 \\
\hline \multicolumn{3}{|c|}{ Average Deflection 8.218 centimeters } \\
\hline \multirow{3}{*}{\multicolumn{2}{|c|}{$\begin{array}{l}\text { Specific Inductive Capacity } \\
\text { Accepted Value } \\
\text { Percentage Error }\end{array}$}} & 2.022 \\
\hline & & 2.288 \\
\hline & & 11.6 \\
\hline
\end{tabular}

